\title{
Correction to: Studying the Potentiality of Using Digital Gaussian Pyramids in Multi-spectral Satellites Images Classification
}

\author{
A. Serwa ${ }^{1}$ (D)
}

(C) Indian Society of Remote Sensing 2020

Correction to: Journal of the Indian Society of Remote Sensing https://doi.org/10.1007/s12524-020-01173-w

In the original article, the author (A. Serwa) name has been published incorrectly. The correct complete name should be A. Serwa.

The original article can be found online at https:// doi.org/10.1007/s12524-020-01173-w.

\footnotetext{
$\triangle$ A. Serwa

Dr.A.Serwa@m-eng.helwan.edu.eg;

Ahmed_serwa@yahoo.com

1 Faculty of Engineering in El-Mataria, Helwan University, Cairo, Egypt
} 